\title{
Symptoms related to asthma and chronic bronchitis in three areas of Sweden
}

\author{
E. Björnsson*, P. Plaschke**, E. Norrman+, C. Janson*, B. Lundbäck+, A. Rosenhall+, \\ N. Lindholm**, L. Rosenhall+, E. Berglund ${ }^{++}$, G. Boman*
}

Symptoms related to asthma and chronic bronchitis in three areas of Sweden. E. Björnsson, P. Plaschke, E. Norrman, C. Janson, B. Lundbäck, A. Rosenhall, N. Lindholm, L. Rosenhall, E. Berglund, G. Boman. CERS Journals Ltd 1994.

ABSTRACT: Does the prevalence of respiratory symptoms differ between regions? As a part of the European Community Respiratory Health Survey, we present data from an international questionnaire on asthma symptoms occurring during a 12 month period, smoking and symptoms of chronic bronchitis. The questionnaire was mailed to 10,800 persons aged $20-44$ yrs living in three regions of Sweden (Västerbotten, Uppsala and Göteborg) with different environmental characteristics. The total response rate was $86 \%$.

Wheezing was reported by $20.5 \%$, and the combination of wheezing without a cold and wheezing with breathlessness by $7.4 \%$. The use of asthma medication was reported by $5.3 \%$. Long-term cough and/or morning cough together with problems with phlegm was reported by $12.8 \%$; the prevalence being highest in the most polluted area (Göteborg). When using multivariate analysis, no significant difference in asthma-related symptoms was found between the centres. Women reported cough more frequently, but otherwise gender did not influence symptom prevalence.

Our results indicate that bronchitis symptoms occur more frequently in Göteborg, the most polluted of the Swedish centres, but that the prevalence rates of asthmarelated symptoms do not differ between these three regions. Eur Respir J., 1994, 7, 2146-2153.
*Dept of Lung Medicine and Asthma Research Center, Akademiska sjukhuset, Uppsala University, Uppsala, Sweden. **Asthma and Allergy Research Center, Sahlgren's Hospital, University of Göteborg, Göteborg, Sweden. +Dept of Pulmonary Medicine and Allergology, University Hospital of Northern Sweden, Umeå, Sweden. ++Dept of Pulmonary Medicine, Sahlgrenska University Hospital, Göteborg, Sweden.

Correspondence: E. Björnsson, Dept of Lung Medicine, Akademiska sjukhuset, S75185 Uppsala, Sweden

Keywords: Asthma

bronchitis

epidemiology

Received: July 131993

Accepted after revision August 91994
Epidemiological studies in many countries, on children [1] and adults [2-4], using both questionnaires and bronchial provocation tests, indicate a rise in asthma prevalence during the last few decades [5-9]. Attempts to ascribe this change to factors such as diagnostic transfer or changes in hospital admission policies have generally proved inadequate $[3,10]$. Some investigators have suggested that the prevalence of asthma may differ between $[11,12]$ and even within countries [13], implying the influence of environmental factors. Studies in Sweden have suggested that the prevalence of asthma symptoms is higher in northern regions [14, 15].

The European Community Respiratory Health Survey (ECRHS) is a multinational survey with the aim of estimating the prevalence of asthma-like symptoms, atopy and bronchial lability, and also the variation in exposure to suspected risk factors and in the treatment of asthma in Europe. Forty eight centres are participating, each with a study area with clear geographic and administrative boundaries. Sweden participates with three such centres.

In ECRHS a modification of the International Union Against Tuberculosis and Lung Disease (IUATLD) questionnaire has been used. This questionnaire has been validated against bronchial hyperresponsiveness as an available objective measure to provide a way around cultural and terminological obstacles in multinational studies $[16,17]$.

In this report, we describe the Swedish results of the first part of the study, conducted as a postal questionnaire on airway symptoms. The three centres differ both in climate and in degree of ambient air pollution, as well as in socioeconomic status of their populations. The aim of this part of our study was to determine whether any geographic differences exist in the prevalence of respiratory symptoms within Sweden.

\section{Materials and methods}

\section{Subjects}

The population sample in each area comprised 1,800 men and 1,800 women, aged 20-44 yrs, randomly chosen from the county council population register in the three areas. The study was approved by the three local Ethics Committees and by the Swedish Data Protection Board.

\section{The questionnaire}

The questionnaire used was the ECRHS modified version of the IUATLD questionnaire $[16,17]$ and includes 
seven questions (Q) commonly related to the diagnosis of asthma (table 1). All questions were translated into Swedish and translated back into English in order to eliminate linguistic bias. The structure of the international part of the questionnaire reflects the period prevalence of airway symptoms in the study population (symptoms during the last 12 months). In addition, five questions on bronchitis-related symptoms and smoking, based on the British Medical Research Council (BMRC) questionnaire, were included in the Swedish questionnaire. These questions have been tested for validity and reliability [18]. The questions are shown in Appendix 1, and will be referred to in the following text by the numbers given in the Appendix.

The questionnaire was mailed to the chosen participants in December 1990, with a letter of explanation and a reply paid envelope. A reminder was mailed after 10 days, and new questionnaires were sent after 1 month and 2 months if no reply was received.

\section{Classifications}

Symptomatic individuals were divided into two groups according to the following definitions: those reporting use of asthma medication or having had an attack of asthma during the previous year (Q5 or Q6) were classified as having an asthma-related disorder (AD). Also positive answers to questions 1 and $1 \mathrm{a}$ and $1 \mathrm{~b}$, i.e. individuals who reported wheeze occurring in the absence of colds, were combined to form a complex of asthmatic symptoms (AS). Those reporting problems with phlegm and also long-term cough and/or morning cough (Q11 and/or Q12, and Q13) were classified as having bronchitis symptoms (BS).

\section{Study areas}

Demographic data were obtained from the Department of Statistics of the respective county council office. The centres (fig. 1) comprised from north to south:

A. Southern and western parts of the county of Västerbotten (Umeå and Lycksele health care districts), a region with both urban (number of persons included $(n)=1788 ; 50 \%)$ and rural areas $(n=1812 ; 50 \%)$.

B. Municipality of Uppsala, a medium sized city, where the participants included people both from the inner city $(n=2667 ; 74 \%)$ and from the surrounding countryside $(n=933 ; 26 \%)$;

C. Göteborg, Sweden's second largest city. The study area comprised the northern part of the city on the island of Hisingen $(n=3600 ; 100 \%)$. In this area there was a larger number of immigrants, and the annual income per inhabitant was lower than in the other two centres (fig. $1)$.

\section{Data on meteorological and pollutional factors}

General aspects. In Västerbotten, the climate is subarctic (table 2), and industrial pollution is low. Occasionally, during periods of thermal inversion, high levels of soot from woodstoves and other sources of combustion occur.

In Uppsala, the temperature is moderate. It is mostly a university city and air pollution from industrial sources is low.

In Göteborg, the climate, by Scandinavian standards, is mild and the level of pollution from motor vehicles and factory outlets is higher than in the other two Swedish areas.

Meteorological data were obtained from the Swedish Meteorological Institute and included measurements of temperature and humidity.

Table 1. - Positive answers on airway symptoms, medication and smoking as \% of participants in each region

\begin{tabular}{|c|c|c|c|c|}
\hline \multirow{2}{*}{$\begin{array}{l}\text { Question } \\
\text { No. } \\
\text { Last } 12 \text { months }\end{array}$} & \multirow[t]{2}{*}{$\begin{array}{c}\text { Västerbotten } \\
\begin{array}{c}(\mathrm{n}=3294) \\
\%\end{array}\end{array}$} & \multirow[t]{2}{*}{$\begin{array}{c}\text { Uppsala } \\
(\mathrm{n}=3147) \\
\%\end{array}$} & \multicolumn{2}{|c|}{$\begin{array}{c}\text { Göteborg } \\
(\mathrm{n}=2884) \\
\%\end{array}$} \\
\hline & & & & \\
\hline 1. Wheezing & 19.8 & 19.0 & 23.0 & $* * *$ \\
\hline 1a. Breathless while wheezing & 11.2 & 10.3 & 12.4 & $*$ \\
\hline 1b. Wheezing without cold & 12.2 & 11.4 & 13.5 & $*$ \\
\hline 2. Woken by chest tightness & 10.4 & 9.7 & 14.7 & $* * *$ \\
\hline 3. Woken by attacks of breathlessness & 4.3 & 5.0 & 7.2 & $* * *$ \\
\hline 4. Woken by attacks of cough & 26.9 & 25.4 & 28.5 & $*$ \\
\hline 5. Asthma attack & 3.3 & 3.3 & 3.1 & \\
\hline Current asthma medication & 6.2 & 4.9 & 4.8 & $*$ \\
\hline 7. Hay fever/allergic rhinitis & 21.1 & 22.2 & 22.2 & \\
\hline \multicolumn{5}{|l|}{ Questions particular to the Swedish centres } \\
\hline \multicolumn{5}{|l|}{ Usually having } \\
\hline 11. Long-term cough & 15.9 & 16.5 & 19.6 & $* * *$ \\
\hline 12. Morning cough & 12.2 & 11.2 & 15.9 & $* * *$ \\
\hline 13. Productive cough & 19.6 & 18.3 & 22.2 & $* * *$ \\
\hline 16. Current smokers & 31.2 & 33.8 & 42.3 & $* * *$ \\
\hline 17. Ex-smokers & 16.3 & 14.9 & 16.3 & $* * *$ \\
\hline Q. $\quad 1$ and $1 \mathrm{a}$ and $1 \mathrm{~b}(\mathrm{AS})$ & 7.6 & 6.8 & 7.7 & \\
\hline Q. 5 or $6(\mathrm{AD})$ & 6.8 & 5.9 & 5.5 & \\
\hline Q. (11 and/or 12) and 13 (BS) & 11.9 & 11.7 & 15.1 & $* * *$ \\
\hline
\end{tabular}

Questions shown in Appendix. AS: asthma symptoms; AD: asthma disorder; BS: bronchitis symptoms; Q: question. Chisquared test was used to test for overall difference among the centres; n: number of participants; *: $\mathrm{p}<0.05 ; * * *: \mathrm{p}<0.001$. 


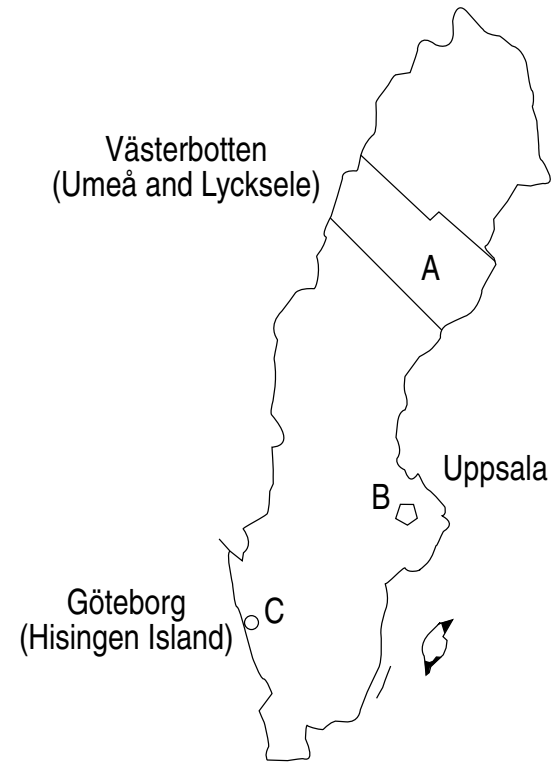

Fig 1. - A map of Sweden with the three centres illustrated, and some demographic characteristics of each centre. A: 171,331 inhabitants; 61,179 aged 20-44 yrs; immigrants 3.2\%; size 46,812 km²; 4 inhabitants. $\mathrm{km}^{2}$; income 121,000 SEK.yr ${ }^{-1}$. B: 167,508 inhabitants; 68,077 aged 20-44 yrs; immigrants 7.5\%; size 2,523 km²; 66 inhabitants $\cdot \mathrm{km}^{2}$; income 133,800 SEK·yr ${ }^{-1}$. C: 109,189 inhabitants; 42,704 aged 20-44 yrs; immigrants $12.3 \%$; size $203 \mathrm{~km}^{2}$; 538 inhabitants $\mathrm{km}^{2}$; income $114,100 \mathrm{SEK} \cdot \mathrm{yr}^{-1}$.

Table 2. - Meteorological parameters, air pollutants and pollen counts in 1990

\begin{tabular}{|c|c|c|c|}
\hline & sterbotten & Uppsala & Göteborg \\
\hline \multicolumn{4}{|l|}{ Meteorological factors } \\
\hline Temperature ${ }^{\circ} \mathrm{C}$ & 4.5 & 7.2 & 9.6 \\
\hline Humidity \% (at 1.00 p.m.) & 69 & 69 & 65 \\
\hline \multicolumn{4}{|l|}{ Air Pollutants $\mu \mathrm{g} \cdot \mathrm{m}^{-3}$} \\
\hline $\mathrm{SO}_{2}$ & n.a. & 3.3 & 6.7 \\
\hline $\mathrm{NO}_{2}^{2}$ & n.a. & 22.8 & 29.4 \\
\hline Black Smoke & n.a. & 8.3 & 10.3 \\
\hline \multicolumn{4}{|l|}{ Pollen Counts $\mathrm{m}^{-3}$ air } \\
\hline Hazel & n.a. & 103 & 30 \\
\hline Alder & 94 & 180 & 55 \\
\hline Birch & 2517 & 12118 & 6185 \\
\hline Grasses & 1093 & 950 & 986 \\
\hline Mugwort & 19 & 164 & 110 \\
\hline
\end{tabular}

Temperatures and humidity is given as annual mean values. Pollutants were measured from October to March, and presented as mean values for the period. Pollen count was measured from March to October, and presented as total of daily averages. n.a.: not available.

Air pollution. Data were obtained from the official environmental control offices in Uppsala and Göteborg (table 2). The county of Västerbotten is large and has internal differences in pollution, and this centre was excluded from this comparison. Measurements of $\mathrm{SO}_{2}$, $\mathrm{NO}_{2}$ and black smoke (black particles less than $10 \mu \mathrm{m}$ in size) were made during the period from October 1990 to March 1991. The procedures of sample collection and analysis were the same in both regions [19]. The method used was molecular diffusion and chemical absorption on an impregnated filter.
Pollen counts. Pollen counts from February 1990 to September 1990 were obtained from the Swedish Pollen Bulletin [20] (table 2). For pollen analysis in Sweden a "Burkard Seven Day Recording Volumetric Spore Trap" is used. Data on the types of pollen that are known to be the most allergenic in this country are given in table 2. This particular pollen season gave a rather low yield compared to the average.

\section{Analysis of late-responders and nonresponders}

A control study was undertaken to estimate how variations in response rates between centres, and a potential difference in symptom prevalence between responders and nonresponders, might affect the results (table 3 ). In this study, $25 \%$ of the nonresponders were randomly chosen, and an attempt was then made to reach as many as possible by phone. Also, a comparison was made between early ( $\leq 4$ weeks) and late ( $>4$ weeks) responders.

\section{Statistical analysis}

Chi-squared test and Fisher's permutation test [21, 22] were used when analysing differences between groups. The latter test includes an exact version of the Chi-squared trend test for a $2 \times n$ table as a special case, and it was applied when comparing two groups with respect to a zero-one variable or with respect to variables with order structure (e.g. age). Odds ratios (OR) with $95 \%$ confidence intervals $(95 \% \mathrm{CI})$ were determined. Logistic regression analysis was performed in order to estimate adjusted odds ratios when taking several variables into account. Two-tailed tests were used.

\section{Results}

\section{Response rates and analysis}

The total response rate was $86 \%$. There was a significantly lower response rate and more late responders in Göteborg than in Västerbotten and Uppsala. Women generally responded earlier and more often compared to the males (table 3 ).

Late responders reported a significantly higher rate of waking with chest tightness and shortness of breath than early responders $(\mathrm{Q} 2: 12.7$ vs $11.0 \%(\mathrm{p}<0.05)$; and $\mathrm{Q} 3$ : 6.6 vs $4.9 \%(\mathrm{p}<0.001))$. Current smoking was more common in late responders than early responders (43.3 vs $32.4 \%(\mathrm{p}<0.001))$. The total number of nonresponders was 1,475 . Of those, 198 had moved, 132 had actively refused or could not participate because of language problems or mental disability, 12 were temporarily away, 4 were of the wrong age, and 1 person had died. For 48 persons, the questionnaire was returned from the post office with no information of a new address. In the remaining 1,080 persons, we have no information on why the questionnaire was not answered.

In the telephone survey, $25 \%$ of the nonresponders from each centre were randomly chosen. Of the 288 
Table 3. - Questionnaire response rates in the three centres, for males and females and early and late responders

\begin{tabular}{|c|c|c|c|c|c|c|}
\hline & \multicolumn{2}{|c|}{ Västerbotten } & \multirow{2}{*}{$\begin{array}{c}\text { Uppsala } \\
\% \\
\end{array}$} & \multirow{2}{*}{$\begin{array}{c}\text { Göteborg } \\
\% \\
\end{array}$} & \multirow{2}{*}{\multicolumn{2}{|c|}{$\begin{array}{c}\text { Total } \\
\%\end{array}$}} \\
\hline & $\mathrm{n}$ & $\%$ & & & & \\
\hline Overall & 9325 & 91.5 & 87.4 & 80.1 & 86.3 & $* * *$ \\
\hline Males & 4510 & 90.1 & 85.1 & 75.4 & 83.5 & $* * *$ \\
\hline Females & 4815 & 93.0 & 89.6 & 84.9 & 89.1 & $* * *$ \\
\hline$\leq 4$ weeks & 6555 & 81.9 & 67.7 & 63.0 & 71.2 & $* * *$ \\
\hline 5-8 weeks & 1558 & 11.6 & 25.9 & 13.3 & 16.9 & $* * *$ \\
\hline$>8$ weeks & 1088 & 6.5 & 6.4 & 23.6 & 11.8 & $* * *$ \\
\hline
\end{tabular}

Chi-squared test was used to test for overall difference among the centres, $* * *: \quad \mathrm{p}<0.001$.

persons selected, 138 (48\%) were reached, and 89 agreed to answer the questionnaire. Of those not reached, 114 had no telephone number, 22 had moved, and 47 did not answer despite repeated calls. Amongst those who could be reached and answered the questionnaire, there were no significant differences in symptom prevalence as compared to other responders.

\section{Questionnaire findings}

The overall prevalence of asthma-related disorder (AD) was $6.1 \%$, of asthmatic symptoms (AS) $7.4 \%$, and of bronchitis symptoms (BS) $12.9 \%$. Of the individuals with $\mathrm{AD}, 48 \%$ had AS. Of the individuals with BS, $22 \%$ had AS. Of the individuals with $\mathrm{AD}, 31 \%$ had BS.

\section{Univariate analysis}

The prevalence of $\mathrm{AD}$ was significantly more common in the younger age groups $(\mathrm{p}<0.05)$. AD did not show any relationship to sex or smoking, but a highly signifi- cant relation to rhinitis. Among individuals with AD, $69.6 \%$ reported having allergic rhinitis compared to $18.6 \%$ in subjects without $\mathrm{AD}$ (OR 10.1; 95\% CI 8.4-12.2). No significant difference in the prevalence of $\mathrm{AD}$ was found between centres (table 1).

There was no relationship between AS and age, gender or centre. Current smoking, as compared to former and lifetime nonsmoking, was significantly related to AS (OR 1.5; 95\% CI 1.3-1.7) (table 4). Among individuals with $\mathrm{AS}, 49.9 \%$ reported allergic rhinitis compared to $19.5 \%$ in individuals without AS (OR 4.1; $95 \%$ CI 3.5-4.8).

Cough (Q4, Q11 and Q12) was less common in the younger age groups, than in older individuals $(\mathrm{p}<0.01$, $\mathrm{p}<0.05$ and $\mathrm{p}<0.001$, respectively; Chi-squared trend test). The rate of BS was not significantly different between age groups and there was no difference between men and women. There were, however, more female smokers (OR 1.1; 95\% CI 1.04-1.2) especially in the younger age groups. Also, significantly more women reported long-term and nocturnal cough (OR 1.7; 95\% CI 1.5-2.0). This difference was found both among smokers and nonsmokers (fig. 2). BS showed a highly significant relation to smoking (OR 3.2; 95\% CI 2.3-3.7). Current active smoking caused an increase in almost all symptoms, but a history of previous smoking did not show any relation to symptoms (table 4). Among individuals with BS, $29.8 \%$ reported allergic rhinitis compared to $20.5 \%$ in individuals without BS (OR 1.6; 95\% CI 1.4-1.9). Using Uppsala as a reference centre, BS was found to be most frequent in Göteborg (OR 1.3; $95 \%$ CI 1.2-1.5)

Allergic rhinitis was significantly more often reported in the younger age group than in older individuals $(p<0.05$, Chi-squared trend test). No difference was seen in gender or smoking habits between those with and without rhinitis. The persons with allergic rhinitis had a significant increase in wheezing as well as all other symptoms.

Table 4. - Positive answers on airway symptoms, and medication in relation to smoking

\begin{tabular}{|c|c|c|c|c|}
\hline $\begin{array}{l}\text { Question } \\
\text { No. }\end{array}$ & $\begin{array}{l}\text { Lifetime nonsmokers } \\
\qquad \begin{array}{c}(\mathrm{n}=4533) \\
\%\end{array}\end{array}$ & $\begin{array}{c}\text { Ex-smokers } \\
(\mathrm{n}=1473) \\
\%\end{array}$ & $\begin{array}{c}\text { Current smokers } \\
(\mathrm{n}=3319) \\
\%\end{array}$ & $\begin{array}{c}\chi^{2} \\
\text { trend } \\
\text { test }\end{array}$ \\
\hline 1. Wheezing & 14.6 & 16.5 & 30.6 & $* * *$ \\
\hline 1a. Breathless while wheezing & 8.4 & 9.4 & 16.1 & $* * *$ \\
\hline 1b. Wheezing without cold & 8.8 & 8.1 & 19.1 & $* * *$ \\
\hline 2. Woken by chest tightness & 9.2 & 11.0 & 15.0 & $* * *$ \\
\hline 3. Woken by attacks of breathlessness & 4.7 & 4.7 & 6.8 & $* * *$ \\
\hline 4. Woken by attacks of cough & 23.1 & 23.0 & 33.5 & $* * *$ \\
\hline 5. Asthma attack & 3.4 & 3.2 & 3.1 & \\
\hline 6. Current asthma medication & 5.4 & 6.2 & 4.9 & \\
\hline 7. Hay-fever/allergic rhinitis & 23.4 & 22.5 & 19.0 & $* * *$ \\
\hline 11. Long-term cough & 13.9 & 14.4 & 22.9 & $* * *$ \\
\hline 12. Morning cough & 6.9 & 7.0 & 23.9 & $* * *$ \\
\hline 13. Productive cough & 13.7 & 14.7 & 30.6 & $* * *$ \\
\hline Q. $\quad 1$ and $1 \mathrm{a}$ and $1 \mathrm{~b}(\mathrm{AS})$ & 7.6 & 5.8 & 10.3 & $* * *$ \\
\hline Q. 5 or $6(\mathrm{AD})$ & 6.4 & 6.7 & 5.8 & \\
\hline Q. (11 and/or 12) and 13 (BS) & 7.8 & 8.1 & 21.6 & $* * *$ \\
\hline
\end{tabular}

AS: asthma symptoms; AD: asthma disorder; BS: bronchitis symptoms; Q: question. Chi-squared trend test was used to test for the influence of smoking, $* * *: \quad \mathrm{p}<0.001$. 


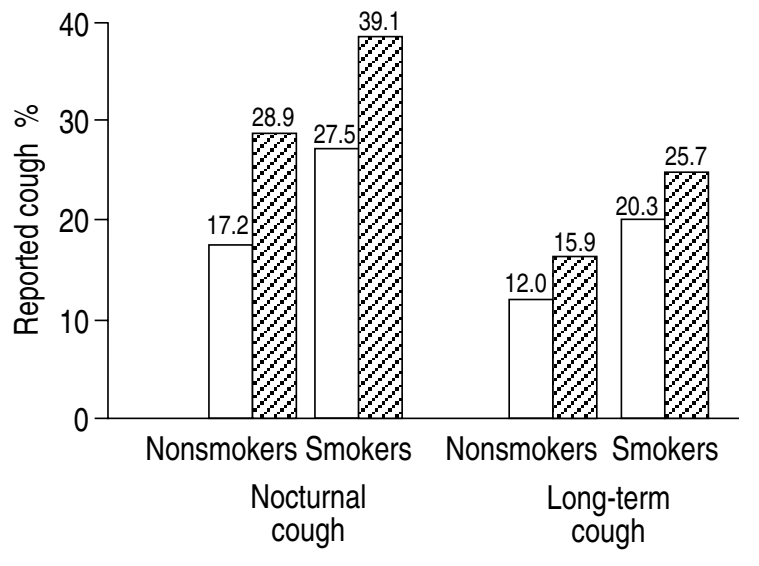

Fig 2. - Reported cough (questions 4 and 8). Differences between sexes and smokers versus nonsmokers (nonsmokers $=$ ex-smokers + lifetime nonsmokers) $\square$ : male; $\mathscr{Z}$ : female.

Of the individuals with rhinitis, $19.5 \%$ had $\mathrm{AD}$ and $17.5 \%$ had BS, but of those without rhinitis, $2.3 \%$ had AD and $11.5 \%$ had BS $(\mathrm{p}<0.001)$. There was no significant difference in prevalence of reported rhinitis between the centres (table 1).

\section{The results of multivariate analysis}

Analysis of the influence of allergic rhinitis, age, gender, smoking and geographical area on respiratory symptoms is shown in table 5. AS, AD and BS were used as dependent variables. Reported allergic rhinitis was positively related to all three dependent variables $(\mathrm{p}<0.001)$. Current smoking increased the prevalence of $\mathrm{AD}$ and $\mathrm{BS}$ $(\mathrm{p}<0.001)$. The prevalence of AD decreased with increased age $(\mathrm{p}<0.01)$. Living in Göteborg was positively related to $\mathrm{BS}(\mathrm{p}<0.05)$.

The influence of sex and smoking on nocturnal cough (Q4) and long-term cough (Q11) was analysed. Being female was an independent risk factor for both nocturnal cough (OR 1.8; 95\% CI 1.7-2.0) and long-term cough (OR 1.4; 95\% CI 1.2-1.5) $(\mathrm{p}<0.001)$. Current smoking was also associated with a higher prevalence of nocturnal cough (Q4) (OR 1.7; 95\% CI 1.5-1.8) and long-term cough (Q11) (OR 1.8; 95\% CI 1.6-21) $(\mathrm{p}<0.001)$.

\section{Discussion}

The purpose of this analysis was to test the hypothesis that the patterns of respiratory symptoms differ between regions in Sweden. We found no significant difference between centres in symptoms related to asthma (AS), or self-reported asthma and use of asthma medication (AD), whilst Göteborg had a higher reported rate of symptoms related to chronic bronchitis (BS).

Clearly no definite diagnosis of an obstructive lung disease can be based solely on a questionnaire such as this. We still felt it illustrative to roughly divide symptomatic individuals into three groups; one having an "asthma-related" disorder (AD), another asthma symptoms (AS), and a third bronchitis symptoms (BS). The definition of AS does not rely on a diagnosis made by the patient or physician, but on reported symptoms. This combination of symptoms has been used by other investigators [23]. It identifies individuals who wheeze and are breathless, whilst not having a cold. Observed regional differences are, therefore, unlikely to depend merely upon possible variation in diagnostic procedures.

\section{Response analysis}

An overall response rate of $86 \%$ is commonly judged to permit a generalization of the results to the general population. However, there were significant differences in response rates between centres (table 3). The lower response rate in Göteborg may be due to the larger number of immigrants with language problems in this area.

Table 5. - Results of logistic regression analysis of the influence of rhinitis, age, gender, smoking and geographical area on the prevalence of respiratory symptoms

\begin{tabular}{|c|c|c|c|c|c|c|}
\hline & \multicolumn{2}{|c|}{$\mathrm{AD}$ (Q5 and/or 6) } & \multicolumn{2}{|c|}{ AS (Q1, 1a and 1b) } & \multicolumn{2}{|c|}{ BS (Q11 and/or 12, and 13) } \\
\hline & OR & $95 \% \mathrm{CI}$ & OR & $95 \% \mathrm{CI}$ & OR & $95 \% \mathrm{CI}$ \\
\hline Rhinitis & 10.1 & $(8.4-12.2)^{* * *}$ & 4.4 & $(3.8-5.2)^{* * *}$ & 1.8 & $(1.5-2.1)^{* * *}$ \\
\hline \multicolumn{7}{|c|}{ Age (compared to $20-24 \mathrm{yrs}$ ) } \\
\hline $25-29 \mathrm{yrs}$ & 0.9 & $(0.9-1.0)^{*}$ & 1.0 & $(0.9-1.0)$ & 1.0 & $(1.0-1.1)$ \\
\hline $30-34$ yrs & 0.8 & $(0.7-0.9)^{*}$ & 1.0 & $(0.9-1.1)$ & 1.0 & $(1.0-1.1)$ \\
\hline $35-39$ yrs & 0.7 & $(0.6-0.9)^{* *}$ & 0.9 & $(0.8-1.1)$ & 1.1 & $(0.9-1.2)$ \\
\hline $40-44$ yrs & 0.7 & $(0.5-0.9)^{* *}$ & 0.9 & $(0.7-1.1)$ & 1.1 & $(0.9-1.3)$ \\
\hline \multicolumn{7}{|c|}{ Sex (compared to females) } \\
\hline Males & 0.9 & $(0.7-1.1)$ & 1.1 & $(0.9-1.2)$ & 0.9 & $(0.8-1.1)$ \\
\hline \multicolumn{7}{|c|}{ Smoking (compared to nonsmokers) } \\
\hline Ex-smoker & 1.2 & $(0.9-1.5)$ & 1.0 & $(0.7-1.3)$ & 1.0 & $(0.8-1.2)$ \\
\hline Current smoker & 0.9 & $(0.8-1.1)$ & 1.9 & $(1.6-2.3)^{* * *}$ & 3.1 & $(2.7-3.6)^{* * *}$ \\
\hline \multicolumn{7}{|c|}{ Centre (compared to Uppsala) } \\
\hline Västerbotten & 1.2 & $(0.9-1.5)$ & 1.2 & $(0.99-1.4)$ & 1.1 & $(0.9-1.2)$ \\
\hline Göteborg & 0.9 & $(0.8-1.2)$ & 1.1 & $(0.9-1.4)$ & 1.2 & $(1.02-1.4)^{*}$ \\
\hline
\end{tabular}

Adjustment for some possible confounding factors (age, gender, smoking and centre) has been made when calculating odds ratio (OR) and 95\% confidence interval $(95 \% \mathrm{CI})$. AD: asthma-related disorder; AS: asthmatic symptoms; BS: bronchitis symptoms. *: $\mathrm{p}<0.05 ; * *: \mathrm{p}<0.01 ; * * *: \mathrm{p}<0.001$. 
We approached the problem of nonresponse in two different ways. Firstly, we looked for trends in the answer pattern between early and late responders. A higher rate of some symptoms (Q2 and Q3) and of smoking, but not of $\mathrm{AD}, \mathrm{AS}$ or $\mathrm{BS}$, was found amongst late responders. Secondly, we chose $25 \%$ of the nonresponders randomly, and attempted to reach as many of them as possible by phone. The 89 individuals reached had a symptom profile no different from that of the other responders.

Although women responded both sooner and more often than men, no difference in symptom prevalence, with the exception of cough, was found.

\section{Comparison between centres}

Some studies on asthma epidemiology have revealed what seems to be a geographic difference in the prevalence of asthma [2, 12, 13, 18, 24-27]. In a review, CoOKson [11] concluded that there are true differences in cumulative prevalence of asthma-like illnesses between countries, and suggested that they could be explained by environmental variations. In Sweden, a number of studies have focused on the prevalence of asthma $[9,15$, $18,25,28]$, and in this country as well as some others it has been proposed that this prevalence might differ between regions [14, 15, 18]. ÅBERG [14] found the prevalence of asthma and allergic rhinitis to be highest among those born in the northernmost provinces of the country, and, in a recent study, LARSON et al. [15] found differences both in reported respiratory symptoms and in the consumption of drugs for asthma, between two neighbouring counties. Despite differences in some meteorological parameters, as well as in the levels of three commonly measured air pollutants, between the centres in our study (table 2), the inter-region variations in the prevalence of most asthma symptoms were not significant after taking into account multiple variables (table 5). This study, therefore, does not support the findings of previous investigators $[14,15]$.

The rate of all BS symptoms was higher in Göteborg than in Västerbotten or Uppsala. This difference remained significant after correction for smoking. One possible explanation for this is the higher level of air pollution in Göteborg. However, we have no data on individual exposure and no reliable data on the exposure of the study population in Västerbotten, although pollution in the area as a whole, is low. Other explanations may include a higher rate of passive smoking, differences in climate, ethnic back-ground, or socioeconomic status.

\section{Questionnaire findings}

Not surprisingly, BS showed a highly significant relationship to active smoking (table 4). AD did not relate to smoking at all, and previous smoking did not seem to have any influence on the prevalence of symptoms (table 4). AS was related to smoking, and it could be argued that these symptoms reflect bronchial hyperreactivity (BHR) whether induced by tobacco smoke or allergic inflammation, and thus are nonspecific. Seventy percent of the individuals with $\mathrm{AD}$ and $50 \%$ with $\mathrm{AS}$ reported allergic rhinitis, as opposed to $30 \%$ of those with $\mathrm{BS}$ and $22 \%$ of the total population sample. This implies that in this population, aged 20-44 yrs, AD and AS are commonly associated with symptoms of allergic disease. That BS was related to rhinitis is probably due to the overlap between AS and BS.

Of most symptoms, there were no significant differences in prevalence rates between the sexes (data not shown). An exception, however, was a pronounced female dominance in reported cough (fig. 2). The reasons for this are obscure. Studies on upper airway symptoms have revealed that women report symptoms of mucosal irritation more often than men [29], and cough as a side-effect of treatment with angiotensin-converting enzyme inhibitors is more often reported by women [30]. To our knowledge, the reasons for these discrepancies have not been elucidated. In their assessment of the influence of the psychological status on respiratory symptoms, DALES et al. [31] found that persistent cough was significantly related to anxiety symptoms, and the latter to be more frequent among women. The same connection with anxiety, however, also applied to other airway symptoms, such as chronic phlegm and episodes of wheezing, the prevalence of which had no relation to gender in our study. Alternatively, women, who spend more time in the home, may be more exposed to indoor allergens and pollutants and to respiratory infections transmitted from their children, than men are. Women may have a higher prevalence of nonspecific BHR [32]. We feel that this issue deserves to be looked into in more detail.

\section{Increase in asthma prevalence}

A review of the current literature suggests that in some populations the prevalence of childhood asthma may have increased over the last decade $[1,5,10,33]$, and in adults the available data suggest the same $[6,7,9,14]$. Some Swedish studies have found a rise in diagnosed asthma [14], and in prescription of asthma drugs and asthma mortality [34].

Two earlier studies have focused on asthma epidemiology at two of our cities. In 1967, IRNELL and KiviLOOG [35] assessed the prevalence of asthma in the county of Uppsala by means of a questionnaire and a subsequent interview and medical examination. An estimated prevalence rate of $2.3 \%$ was obtained according to the definitions of the American Thoracic Society at that time. In the same year, JUHLin and WILHELMSEN [36] reported a similar prevalence rate $(2.0 \%)$ in a study of over 2,000 men and women in Göteborg. Both of these studies measured cumulative prevalence, as opposed to period prevalence (symptoms in the last 12 months) in the present study. In the study in Uppsala, asthma defined as "quiescent", i.e. no symptoms in the last 12 months, had a prevalence of $1.0 \%$, making the prevalence of active asthma only $1.3 \%$. The screening questions on asthma used must be considered as "broad" and cannot be directly related to any of the questions in the present study. Also the age range was different (30-64 yrs). This makes direct comparison difficult, but the 1967 number of $1.3 \%$ 
must, nevertheless, be considered low, when compared to the $5.9 \% \mathrm{AD}$ and $6.8 \% \mathrm{AS}$ in Uppsala today.

In conclusion, our results indicate that there are no significant differences in the prevalence rates of asthmarelated symptoms between these three areas, but that symptoms of chronic bronchitis show a significant relationship to areas of high pollution. Furthermore, the results support the conclusion drawn by others that the prevalence of asthma is increasing in Sweden.

\begin{abstract}
Acknowledgements: These results are from a national analysis of data collected for the European Community Respiratory Health Survey. Any final international comparison may use a different form of analysis. The authors thank A. Odén (Dept of Mathematics, University of Göteborg) for statistical advice. The study was made possible by grants from the Swedish Heart Lung Foundation, the Swedish Medical Research Council, the Swedish Association against Asthma and Allergy, the Associations against Asthma and Allergy in Uppsala and in Göteborg, the Herman Kreftings Foundation, the Bror Hjerpstedt Foundation, and the County Councils of Uppsala and Göteborg.
\end{abstract}

\section{Appendix}

\section{Questionnaire}

The following questions are common to all centres of the ECRHS:

Q1. Have you had wheezing or whistling in your chest at any time in the last 12 months?

Q1a. Have you been at all breathless when the wheezing noise was present?

Q1b. Have you had this wheezing or whistling when you did not have a cold?

Q2. Have you woken up with a feeling of tightness in your chest at any time in the last 12 months?

Q3. Have you been woken by an attack of shortness of breath at any time in the last 12 months?

Q4. Have you been woken by an attack of coughing at any time in the last 12 months?

Q5. Have you had an attack of asthma in the last 12 months?

Q6. Are you currently taking any medicine (including inhalers, aerosols or tablets) for asthma?

Q7. Do you have any nasal allergies including "hay fever"

Questions 8-10 concerned age, sex and date. In Sweden the questionnaire included seven additional questions on pets, smoking habits and symptoms relating to chronic bronchitis [18]. The questions on pets (Q14 and Q15) are not analysed further in this article.

Q11. Have you in recent years had troubles with long term cough?

Q12. Do you usually cough in the morning?

Q13. Do you usually cough up phlegm?

Q16. Do you smoke? (answer yes even if you only smoke a few cigarettes or pipes per week, or if you quit smoking for less than one year).

Q17. Are you an ex-smoker? (quit smoking for more than one year).

\section{References}

1. Ninan T, Russel G. Respiratory symptoms and atopy in Aberdeen schoolchildren: evidence from two surveys 25 years apart. Br Med $J$ 1992; 304: 873-875.

2. Krzyzanowski M, Lebowitz MD. Changes in chronic respiratory symptoms in two populations of adults studied longitudinally over 13 years. Eur Respir J 1992; 5: 12-20.

3. Burney PGJ, Papacosta AO, Withey CH, Colley JRT, Holland WW. Hospital admission rates and the prevalence of asthma symptoms in 20 local authority districts. Thorax 1991; 46: 574-579.

4. Peat JK, Haby M, Spijker J, Berry G, Woolcock A. Prevalence of asthma in adults in Busselton, Western Australia. Br Med J 1992; 305: 1326-1329.

5. Sears MR. Epidemiological trends in bronchial asthma. In: Kaliner MA, Barnes PJ, Persson CG, eds. Asthma. Its Pathology and Treatment. New York, Dekker, 1991; pp. $1-50$.

6. Fleming DM, Crombie DL. Prevalence of asthma and hay fever in England and Wales. Br Med J 1987; 294 : 279-283.

7. Evans R, Mullally DI, Wilson RW, et al. National trends in the morbidity and mortality of asthma in the US. Chest 1987; 91: 65-78S.

8. Burr ML, Butland BK, King S, Vaughan-Willams E. Changes in asthma prevalence: two surveys 15 years apart. Arch Dis Child 1989; 64: 1452-1456.

9. Boman G. Epidemiology of obstructive lung diseases in the Nordic Countries. Eur Respir Rev 1991; 1: 316-320.

10. Burney PGJ, Chinn S, Rona RJ. Has the prevalence of asthma increased in children? Evidence from the national study of health and growth 1973-1986. Br Med J 1990; 300: 1306-1310.

11. Cookson JB. Prevalence rates of asthma in developing countries and their comparison with those in Europe and North America. Chest 1987; 6: 97-103S.

12. Charpin D, Vervloet D, Charpin J. Epidemiology of asthma in western Europe. Allergy 1988; 43: 481-492.

13. Charlton JRH, Hartley RM, Silver R, Holland WW. Geographical variation in mortality from conditions amenable to medical intervention in England and Wales. Lancet 1983; 8326 (pt 1): 691-696.

14. Åberg N. Asthma and allergic rhinitis in Swedish conscripts. Clin Exp Allergy 1989; 19: 59-63.

15. Larsson L, Boethius B, Uddenfeldt M. Differences in utilization of asthma drugs between two neighbouring Swedish provinces: relation to symptom reporting. Eur Respir J 1993; 6: 198-203.

16. Burney PGJ, Laitinen LA, Perdrizet S, et al. Validity and repeatability of the IUATLD (1984) Bronchial Symptoms Questionnaire: an international comparison. Eur Respir J 1989; 2: 940-945.

17. Burney PGJ, Chinn S. Developing a new questionnaire for measuring the prevalence and distribution of asthma. Chest 1987; 91: 79-92S.

18. Lundbäck B. Asthma, chronic bronchitis and respiratory symptoms: prevalence and important determinants. Umeå University Medical Dissertations, New Series No. 387, 1993.

19. Institutionen för vatten och luftvårdsforskning (IVL). Halter av svaveldioxid, sot och kvävedioxid i svenska tätorter. Göteborg, 1991; (in Swedish).

20. Dahl Å, Strandhede SO. Pollensäsongen 1990. In: Astma \& Allergi Service, Fisons Pharmaceuticals 1990; pp. 45-50 (in Swedish). 
21. Bradley JW. Distribution-free Statistical Tests London, Prentice-Hall, 1968; pp. 68-86.

22. Oden A, Wedel H. Arguments for Fisher's permutation test. Annals of Statistics 1975; 3: 518-520.

23. Lebowitch MD, Burrows B. Comparison of questionnaires: the BMRC and NHLI Respiratory Questionnaires and a new self-completed questionnaire. Am Rev Respir Dis 1976; 113: 627-635.

24. Åberg N, Engström I, Lindberg U. Allergic diseases in Swedish school children. Acta Pediatr Scand 1988; 78: 246-252.

25. Bråbäck L, Kälvesten L. Prevalence of bronchial asthma among schoolchildren in a Swedish district. Acta Pediatr Scand 1988; 77: 821-825.

26. Sears MR, Rea H, Rothwell RPG, et al. Asthma mortality: comparison between New Zealand and England. $\mathrm{Br}$ Med $J$ 1986; 293: 1342-1345.

27. Keeley DJ, Neill P, Gallivan S. Comparison of the prevalence of reversible airways obstruction in rural and urban Zimbabwean children. Thorax 1991; 46: 549-553.

28. Mikaelsson B, Stjernberg N, Wiman LG. The prevalence of bronchial asthma and chronic bronchitis in an industrialized community in northern Sweden. Scand J Soc Med 1982; 10: 11-16.

29. Skov P, Valbjörn O. The sick-building syndrome in the office environment. The Danish town hall study. Environ Int 1987; 13: 339-349.
30. Moore N, Noblet C, Joannides R, Ollagnier M, Imbs JL, Lagier G. Cough and ACE inhibitors. Lancet 1993; 341: 61.

31. Dales RE, Spitzer WO, Schecther MT, Suissa S. The influence of psychosocial status on respiratory symptom reporting. Am Rev Respir Dis 1989; 139: 1459_ 1463.

32. Trigg CJ, Bennett JB, Tooley M, Sibbald B, D'Souza MF, Davies RJ. A general practice based survey of bronchial hyperresponsiveness and its relation to symptoms, sex, age, atopy, and smoking. Thorax 1990; 45: 866-872.

33. Robertson CF, Heycock E, Bishop J, Nolan T, Olinsky A, Phelan PD. Prevalence of asthma in Melbourne schoolchildren: changes over 26 years. Br Med J 1991; 302: $1116-1118$.

34. Boman G. Changes in asthma morbidity, drug therapy and mortality. In: Pharmacological Treatment of Bronchial Asthma. Workshop. National Board of Health and Welfare. Drug Information Committee, Sweden. 1986; 3: $1-6$.

35. Irnell L, Kiviloog J. Bronchial asthma and chronic bronchitis in a Swedish urban and rural population. Scand J Respir Dis 1968; 66: 1-86S.

36. Juhlin A, Wilhelmsen L. Bronchial asthma and chronic bronchitis in a random population sample. Scand J Respir Dis 1967; 48: 330-342. 